
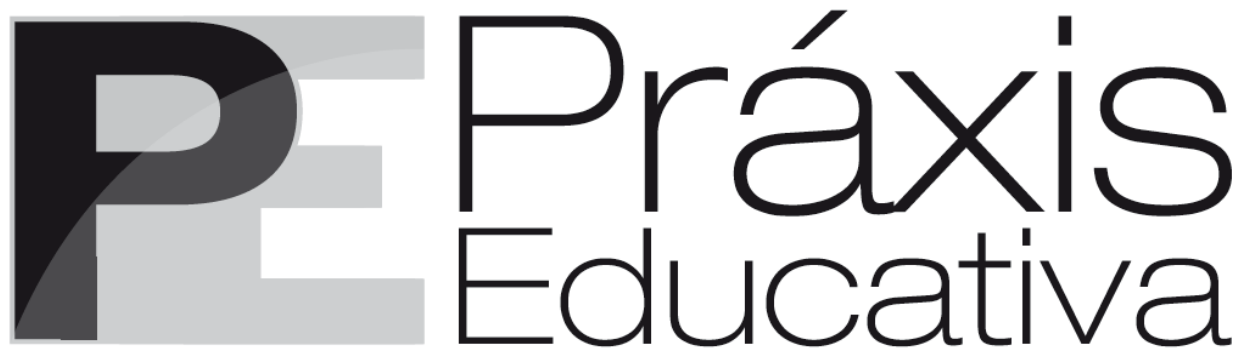

ISSN 1809-4031

elSSN 1809-4309

https://doi.org/10.5212/PraxEduc.v.16.16623.058

\title{
A atualidade do pensamento de Paulo Freire para reinventar as práticas de formação política no âmbito da educação popular
}

\section{The topicality of Paulo Freire's thinking to reinvent practices of political education within the scope of popular education}

\section{La actualidad del pensamiento de Paulo Freire para reinventar las prácticas de formación política en el ámbito de la educación popular}

\author{
Pedro de Carvalho Pontual ${ }^{*}$ \\ iD https://orcid.org/0000-0002-7248-3975 \\ Maria Auxiliadora Delgado Machado \\ iD https://orcid.org/0000-0002-7492-0999
}

\begin{abstract}
Resumo: Este artigo pretende discutir a educação popular no âmbito do Conselho de Educação Popular da América Latina e do Caribe (CEAAL), considerando um de seus pressupostos básicos a formação política. O intuito é mostrar como a presença de Paulo Freire, primeiro presidente do CEAAL, foi fundamental para a formação e a atuação desse grupo ao longo de sua história. Os argumentos fundamentam-se na identificação de categorias freirianas consolidadas na literatura e presentes nos dois mais recentes documentos do CEAAL em 2018 e 2019. Ambos os documentos são produto do coletivo de educadores populares de 21 países da América Latina. Fez-se uma análise léxica simplificada com o software Vayant Tools, a partir da contagem de palavras em cada texto e comparadas aos verbetes de um dicionário sobre a obra freiriana. As seis categorias identificadas contribuem para uma revisão crítica e desafios da formação política hoje na perspectiva da educação popular.
\end{abstract}

Palavras-chave: Paulo Freire. Educação popular. Formação política.

Abstract: This article aims to discuss Popular Education within the scope of the Council of Popular Education of Latin America and the Caribbean (CEAAL), considering one of its basic assumptions the political education. The objective is to show how Paulo Freire's presence, CEAAL's first president, was fundamental to the formation and performance of this group throughout its history. The arguments are

\footnotetext{
${ }^{*}$ Doutor em História da Educação: História, Política e Sociedade pela Pontifícia Universidade Católica de São Paulo (PUC-SP). Mestre em educação: História, Política e Sociedade pela PUC-SP. Professor visitante do PPGEdu da UNIRIO. E-mail: <pcpontual@gmail.com>.

${ }^{* *}$ Doutora em Astronomia pelo Observatório Nacional (MCT), Mestre em Astronomia pelo MCT. Professora do Departamento de Didática da Universidade Federal do Estado do Rio de Janeiro (UNIRIO) e do Programa de PósGraduação em Educação (PPGEdu) da UNIRIO (Mestrado e Doutorado). E-mail: <maria.machado@unirio.br>.
} 
A atualidade do pensamento de Paulo Freire para reinventar as práticas de formação política no âmbito...

based on the identification of Freirean categories consolidated in the literature and present in the two most recent CEAAL documents in 2018 and 2019. Both documents are the product of the collective of popular educators from 21 countries in Latin America. A simplified lexical analysis was carried out with the Vayant Tools software, based on the word count in each text and compared to the entries in a dictionary on Freire's work. The six categories identified contribute to a critical review and challenges of political education today from the perspective of popular education.

Keywords: Paulo Freire. Popular education. Political education.

Resumen: Este artículo tiene la intención de discutir la educación popular en el ámbito del Consejo de Educación Popular de América Latina y el Caribe (CEAAL), considerando o supuestos la formación política. El objetivo es mostrar cómo la presencia de Paulo Freire, primer presidente de CEAAL, fue fundamental para la formación y desempeño de este grupo a lo largo de su historia. Los argumentos se basan en la identificación de categorías freirianas consolidadas en la literatura, y presentes en los dos documentos CEAAL más recientes en 2018 y 2019. Ambos documentos son producto del colectivo de educadores populares de 21 países de América Latina. Se hizo un análisis léxico simplificado con el software Vayant Tools a partir del recuento de palabras en cada texto y comparadas con las entradas de un diccionario sobre la obra de Freire. Las seis categorías identificadas contribuyen a una revisión crítica sobre los desafíos de la formación política hoy en la perspectiva de la educación popular.

Palabras clave: Paulo Freire. Educación popular. Formación política.

\section{Introdução}

O título da chamada para esse dossiê - "Paulo Freire (1921-2021): 100 anos de história e esperança" - é por si só inspirador e nos remete a alguns conceitos da obra freiriana. Seu centenário de nascimento conduz nosso olhar às ideias e aos conceitos que circulam em seus livros, entrevistas e discussões de vários tipos, e a experimentar uma expectativa ansiosa de eventuais releituras para novas abordagens de um ou mais temas. Como o próprio Freire chama atenção na seção "Primeiras Palavras" da obra Pedagogia da autonomia, a partir da "[...] inconclusão do ser humano, de sua inserção num permanente movimento de procura” (FREIRE, 1996, p. 8), é que se rediscute diversos temas tratados anteriormente. Assim sendo, aos assumirmo-nos como sujeitos inconclusivos, entendemos que qualquer releitura da obra freiriana será uma nova leitura, implicará uma nova reflexão, sem dogmas pré-assumidos, mas considerando antigas e novas condições em torno de qualquer que seja o tema.

Uma outra questão ainda relacionada à chamada do dossiê é que seu lançamento ocorreu em torno de meados de março do ano de 2020, um pouco antes do isolamento social que marcou a vida de milhões de pessoas em todo o mundo, devido à pandemia da COVID-19. Tal contexto no âmbito desse dossiê nos leva a seguinte questão: $\mathrm{O}$ que Paulo Freire nos diria sobre esse momento? Com esse questionamento em mente, além de novas leituras e reflexões como dito anteriormente, sentimo-nos motivados a buscar a obra de Freire em momentos de crise e/ou dificuldades de diversas ordens. Do ponto de vista da sua vivência pessoal, desde sua atuação como educador-alfabetizador de adultos em Angicos, Paulo Freire enfrentou quase que imediatamente a prisão, o exílio, o conviver em outros países, e toda a tristeza advinda desses momentos. Do ponto de vista mais geral, do coletivo, ele vivenciou a ditadura e suas consequências no Brasil e em partes da América Latina, as crises dos sistemas socialistas, o avanço cruel do liberalismo em suas mais diversas formas, entre outras várias crises. Todos esses momentos são marcados por muito trabalho, publicações de livros e diversos projetos realizados em diferentes partes do mundo. Em muitas dessas obras, uma palavra destaca-se: "esperança" - e suas variações, adjetivos ou verbos a ela associados. Um exemplo de como esperança é citada nos dicionários é: substantivo feminino confiança de que algo bom acontecerá: esperança de se curar; crença de que um desejo se torne realidade: esperança de casar-se (FERREIRA, 1999).

Práxis Educativa, Ponta Grossa, v. 16, e2116623, p. 1-20, 2021

Disponível em: <https://www.revistas2.uepg.br/index.php/praxiseducativa> 
Na Pedagogia da Esperança, Paulo Freire inicialmente fala-nos de si mesmo: "Não sou esperançoso por pura teimosia, mas por imperativo existencial e histórico" (FREIRE, 1997, p. 5). Freire continua associando esperança e luta:

\begin{abstract}
Não quero dizer, porém que, porque esperançoso, atribuo à minha esperança o poder de transformar a realidade, e, assim convencido parto para o embate, sem levar em consideração os dados concretos materiais, afirmando que minha esperança basta. Minha esperança é necessária, mas não é suficiente. Ela, só, não ganha a luta, mas sem ela a luta fraqueja e titubeia. (FREIRE, 1997, p. 5).
\end{abstract}

Em outro trecho, Freire (1997) recorre ao tempo e à temporalidade para relacionar o esperançar com o tempo presente, que, em diálogo com o passado de nossas raízes étnico-culturais, aponta para o futuro no qual utopias serão materializadas em inéditos viáveis.

Tais considerações foram uma verdadeira inspiração para debruçarmo-nos sobre um tema já consolidado por diversas práticas, de vários grupos, em diferentes ambientes de educação formal, não formal e informal, mas que, em nossa opinião, ainda circula pouco nos meios acadêmicos, em especial no formato de artigos de pesquisa. Esse tema é a educação popular que será aqui discutida a partir de um recorte específico: a educação popular no âmbito do Conselho de Educação Popular da América Latina e do Caribe (CEAAL) a partir da formação política, um dos seus elementos balizadores.

O CEAAL foi fundado em 1982, e seu primeiro presidente foi Paulo Freire. A partir de então, iniciou-se uma dinâmica de estudo e de trabalho com a criação de inúmeros espaços, encontros e redes de reflexão sobre educação popular na América Latina. Em face da conjuntura atual, marcada pelo aprofundamento das injustiças sociais em decorrência da restauração conservadora promovida pelas forças neoliberais e de direita, o CEAAL tem apostado na necessidade de aprofundar e reinventar o legado da educação popular como processo de formação política das classes populares. Com essa posição, o CEAAL entende que a educação popular pode contribuir para uma maior organicidade das lutas travadas pelos movimentos sociais por direitos e contra os retrocessos decorrentes do avanço das políticas neoliberais. Nesse contexto, o CEAAL considera que desenvolver processos de formação política implica construir uma contra-hegemonia popular que fortaleça subjetividades críticas e a participação de forma crítica e criativa das classes populares nos processos de transformação social.

No documento interno de discussão "15 Linhas de Trabalho para uma estratégia de formação política do CEAAL”, de março de 2019, aparece de modo mais sistematizado tal reflexão. Aqui destacamos o entendimento do que comporia uma estratégia de formação política:

\begin{abstract}
Não se trata de realizar uma somatória de atividades nos diferentes países, mas de articular e conferir projeção estratégica e movimentista a processos formativos flexíveis e diversos que geram debates críticos e ações transformadoras através de múltiplos e diversos formatos: cursos, seminários, encontros oficinas, que podem ser presenciais ou à distância e virtuais; também festivais, jornadas, acampamentos, marchas etc. (CEAAL, 2019, p. 9, tradução nossa). ${ }^{1}$
\end{abstract}

Em tempos de pandemia, cresce a discussão entre as organizações e os coletivos que fazem parte da rede de como desenvolver práticas de formação política associadas diretamente às ações de solidariedade às populações mais atingidas pela pandemia e suas consequências socioeconômicas. Trata-se de buscar no ESPERANÇAR freiriano a energia para construir

\footnotetext{
${ }^{1}$ Documento interno de trabalho, título original "15 líneas de trabajo para la estrategia de formación política del CEAAL", não publicado.
} 
A atualidade do pensamento de Paulo Freire para reinventar as práticas de formação política no âmbito...

"inéditos viáveis" que apontem possibilidades de superação da situação atual a partir de um novo horizonte ético, político e pedagógico.

O CEAAL vem evidenciando continuamente as bases da educação popular como um movimento social, cultural, político, educativo e pedagógico a partir de muitas contribuições de membros e de colaboradores em forma de textos e de discussões sobre educação popular que tem circulado desde sua fundação. Autores como Jorge Osório (Chile), Carlos Brandão (Brasil), Carlos Nuñes (México), Alfonso Torres Carrillo (Colômbia) e Oscar Jara (Costa Rica) entre outros, socializam continuamente os resultados de suas pesquisas de modo a contribuir para discussões em diversos fóruns do conselho que, em diálogo com os relatos de experiências vivenciadas por todos os participantes, marcam os documentos oficiais do Conselho - em particular as atas das assembleias. Em outras palavras, os princípios fundantes e direcionadores do CEAAL são fruto de um coletivo com uma forte assinatura empírica.

Nesse sentido, movidos pela iminência do centenário de Paulo Freire e tudo que esse centenário remete, conforme já explanamos, buscamos, nesta pesquisa, contribuir com os educadores e as educadoras populares, mostrando que, além da prática freiriana, os documentos e os textos produzidos no âmbito do CEAAL possuem uma forte assinatura freiriana a partir do grande número de categorias que surgem da obra desse educador. Entendemos que a perspectiva freiriana do CEAAL é continuamente reafirmada nas obras dos pesquisadores citados anteriormente e de tantos outros em seus textos, falas diversas, entrevistas, etc. Entretanto, do ponto de vista didático, consideramos ser relevante apontarmos a presença de Paulo Freire a partir da concretude das palavras/expressões presentes nos documentos do CEAAL e suas respectivas identificações como categorias freirianas. Defendemos aqui que os princípios freirianos foram tão intensamente apropriados pelo coletivo do CEAAL e de tal forma que já se constituem em um vivenciamento contínuo e cotidiano dos membros do conselho. Diante disso, nosso objetivo, neste texto, é evidenciarmos essa apropriação freiriana a partir da identificação das categorias da obra de Paulo Freire que circulam nos documentos produzidos pelo coletivo dos membros, a fim de reafirmá-las de forma mais sistemática como princípios da educação popular no âmbito do CEAAL, frente aos desafios postos na atualidade.

O processo metodológico de uma investigação apresenta-se por diferentes caminhos e em diferentes momentos da pesquisa propriamente dita. Segundo Minayo (2015, p. 14), “[...] a metodologia inclui simultaneamente a teoria da abordagem (o método), os instrumentos de operacionalização do conhecimento (as técnicas) e a criatividade do pesquisador (sua experiência, sua capacidade pessoal e sua sensibilidade)". A autora ressalta, ainda, que: "Na verdade a metodologia é muito mais que técnicas. Ela inclui as concepções teóricas da abordagem, articulando-se com a teoria, com a realidade empírica e com os pensamentos sobre a realidade" (MINAYO, 2015, p. 15).

Dito isso, apresentamos, na próxima seção, um panorama da trajetória da educação popular na América Latina e no Caribe nos últimos 60 anos e sua importância no âmbito do CEAAL. Em seguida, discorremos sobre os caminhos metodológicos desta pesquisa, a análise das categorias definidas e as nossas considerações finais.

\section{Abrindo a roda de conversa: o CEAAL, a história da educação popular na América Latina e os caminhos desta pesquisa}

Tomando como ponto de partida a periodização proposta por Jara (2020) após a fase denominada por antecedentes da educação popular, entre o final do século XIX e a primeira metade do século XX, podemos dizer que o primeiro período da atual compreensão da educação popular

Práxis Educativa, Ponta Grossa, v. 16, e2116623, p. 1-20, 2021

Disponível em: < https://www.revistas2.uepg.br/index.php/praxiseducativa> 
vai desde o final dos anos de 1950 - com a Revolução Cubana - até 1970 com o Governo da Unidade Popular no Chile. Esse período foi marcado pelos seguintes impactos: i) Revolução Cubana em suas ações no campo da Campanha Nacional de Alfabetização; ii) universalização do acesso à educação; e iii) formulações de Paulo Freire de uma pedagogia libertadora e de conscientização que se disseminaram por toda América Latina, convergindo com a Investigaçãoação-participativa (IAP), do sociólogo colombiano Orlando Fals Borda, e o movimento da Teologia da Libertação

A clara opção de classe assumida por Paulo Freire é expressa com a publicação da Pedagogia do oprimido, a qual ampliou a articulação de práticas de educação popular em toda a América Latina, inspiradas em sua pedagogia libertadora, na teologia da libertação e na investigação ação participativa. Esse movimento constituiu o que Jara (2020) identificou como o segundo período da educação popular, que foi do Governo da Unidade Popular no Chile ao triunfo da Insurreição Popular Sandinista na Nicarágua de 1970 a 1979.

Osório (2020) considera que os anos de 1960/1970 constituíram o "ciclo original” e que ali se definiu uma matriz comum de elementos que dizem respeito à educação popular até hoje e que servem para praticar, avaliar, reorientar, refundar a educação popular, dentre os quais destacamos:

1- A educação popular [EP] como movimento cultural associada a organizações de base e movimentos sociais, definindo a pedagogia como a dimensão da aprendizagem de novas formas de pensar, viver, compartilhar e "fazer política";

2- A educação popular como educação inserida na dinâmica social dos setores populares do campo e das cidades e que atribui aos(as) educadores(as) um perfil de mediador, de gerar espaços de aprendizagem, de valorização do vínculo pedagógico (diálogo de saberes) como fonte de libertação, de construção de uma subjetividade crítica e de abertura a uma vida solidária;

3- A EP como uma educação que não fica só na relação capital/trabalho, mas trabalha pedagogicamente a democratização das relações de gênero, as assimetrias culturais na vida cotidiana, a geração de poderes e saberes locais e as manifestações culturais e linguísticas de povos indígenas;

4- A EP como educação, defesa e promoção dos direitos humanos. Três foram as fontes inspiradoras de tal orientação estratégica; a) A Teologia da Libertação e a influência da participação ativa da EP na dimensão educativa da Igreja popular; b) a participação da EP nos processos de renovação da esquerda; c) a incorporação a processos culturais de movimentos sociais que trazem força às dimensões de gênero, da arte e da cultura popular, da economia popular, do desenvolvimento local, do meio ambiente, entre outros;

5- A EP como ação reflexiva fundada numa epistemologia da ação libertadora que assume a investigação-ação-participativa proposta por Orlando Fals Borda da Colômbia e a teoria do conhecimento libertadora de Paulo freire e seu método dialético de "aprender a ler a realidade para transformá-la". (OSÓRIO, 2020, p. 5).

Segundo Osório (2020), essa matriz comum, inspiradora das práticas da educação popular, irá influenciar os movimentos sociais em uma lógica de autonomia cultural entendida como a capacidade de construir alternativas de esquerda a partir da lógica da ação social não necessariamente subordinada a partidos políticos. Isso provocou resistências de certa esquerda tradicional que acreditava que todo processo revolucionário devia ser dirigido por uma vanguarda que se expressava em um partido político. Osório (2020) fala-nos, ainda, que essa teoria autonomista que marcou a educação popular gerou, mais a frente, novos movimentos sociais e uma nova cultura política que devia fundar-se na democracia participativa e no poder popular cidadão.

Com todo esse acumulado que vem dos anos de 1960/1970, chegamos aos anos de 1980, que são marcados, logo de início, pela Insurreição Popular Sandinista (1979) e por seus impactos

Práxis Educativa, Ponta Grossa, v. 16, e2116623, p. 1-20, 2021

Disponível em: <https://www.revistas2.uepg.br/index.php/praxiseducativa > 
A atualidade do pensamento de Paulo Freire para reinventar as práticas de formação política no âmbito...

para a educação popular na Nicarágua e para outros países da América Latina. Jara (2020) sintetiza assim os novos desafios que esse contexto colocava para a educação popular:

A dinâmica dessa nova realidade em que os processos de Educação Popular se envolveram exigiu criar e recriar métodos e técnicas de pesquisa e capacitação, desenhos de estratégias de Educação Popular de alcance massivo e fundamentar toda uma conceituação teórico-metodológica que respondesse às aprendizagens e aos desafios dessa nova realidade na qual se estava participando de forma vital, carregada de admirações e de buscas. (JARA, 2020, p. 118).

Como expressão do crescimento das práticas de educação popular no âmbito de América Latina, foi fundado, em 1982, o Conselho de Educação de Adultos da América Latina (CEAAL), que se constituiu a partir de uma confluência dos processos de educação popular, educação de adultos e pesquisa-ação-participativa de todos os países de nosso continente. Formado, inicialmente, a partir de Organizações não Governamentais (ONGs), o CEAAL teve, conforme já mencionamos, Paulo Freire como primeiro presidente e, em seguida, Orlando Fals Borda, como evidência da articulação entre as práticas de educação popular e de investigação-ação-participativa e da aglutinação de diversos grupos que praticavam a educação popular no continente. Jara (2020) assim se refere ao papel aglutinador e multiplicador do CEAAL naquele período:

O CEAAL, ao promover uma grande quantidade de eventos, gerou um inédito nível de intercâmbio, reflexão e busca de aprendizagens conjuntas. Nesse período acontecem importantes e inesquecíveis encontros latino-americanos que dão lugar à formação de importantes redes de educadores e educadoras que trabalham em todos os rincões da América Latina. (JARA, 2020, p. 130).

Naquela época, além da pesquisa participativa, adquiriram destaque latino-americano duas redes geradas a partir do CEAAL: a Rede de Educação Popular entre Mulheres e a Rede de Educação Popular e Direitos Humanos. Simultaneamente, formaram-se no CEAAL outras redes e grupos de trabalho, a saber: i) trabalho com povos indígenas; ii) comunicação popular; iii) saúde, iv) pesquisa participativa; v) formação de educadores e educadoras etc. Merece destaque a criação do Programa de Apoio à Sistematização e Auto Avaliação na Educação Popular, que mais a frente se consolidou como Programa Latinoamericano de Sistematização de Experiências (PLAS).

No período entre a terceira assembleia de Havana (1994) e a quarta assembleia no Panamá (2000), o CEAAL levou adiante um processo de reflexão, intercambio e debate que ficou conhecido como Refundamentação da Educação Popular (JARA, 2020). Entre os diversos fatores que motivaram essa convocação, estão a crise do socialismo como modelo de referência alternativo; o avanço do neoliberalismo da narrativa que ficou conhecida como o "fim da história"; as inquietações com relação ao esgotamento dos referenciais teóricos fundantes da educação popular para compreender questões como: i) o novo contexto, as novas e diversas práticas e atores sociais e políticos; ii) a separação do político dos debates pedagógicos em torno da geração de processos de aprendizagem; e iii) a abertura para a discussão sobre novos paradigmas no campo das ciências sociais. Segundo Jara (2020), os principais eixos desse debate sobre a refundamentação foram:

a) A crise e a reinvenção de paradigmas.

b) Incidências da globalização e o neoliberalismo na América Latina.

c) Educação popular e sua relação com os movimentos sociais.

d) Educação popular, democratização, cidadania, poder local e políticas públicas.

e) Educação popular e sua dimensão pedagógica diante do político.

Partindo desses temas como eixos que nortearam o debate, vale registrarmos algumas das avaliações acerca da discussão da refundamentação no âmbito do CEAAL. Para Jara (2020), o início do século XXI, marcado pela realização do Fórum Social Mundial de Porto Alegre, deu-se no

Práxis Educativa, Ponta Grossa, v. 16, e2116623, p. 1-20, 2021

Disponível em: <https://www.revistas2.uepg.br/index.php/praxiseducativa> 
contexto da emergência no plano internacional dos movimentos de "alterglobalização" e no plano latino-americano do ciclo de governos progressistas. Isso colocou novos temas para a educação popular vinculados à busca de paradigmas emancipatórios:

Esses dois fatores no contexto internacional e latinoamericano influenciaram as
reflexões, os intercâmbios e os debates no interior do campo da Educação Popular
latinoamericana, superando as discussões mais gerais que se realizaram durante a “
refundamentação" e vendo agora de maneira mais integral a relação entre local/nacional
e o global, colocando atenção aos desafios concretos que enfrentavam as práticas e
recolocando no centro das discussões o tema sentido, identidade e vigência dos processos
de educação popular na América latina. Daí que as temáticas mais recorrentes tenham
sido: a mudança de paradigmas e a Educação Popular; democratização, cidadania, poder
local e Educação popular; Gênero e Educação Popular; multiculturalismo,
interculturalidade educação Popular; Educação Popular sistemas e políticas educativas.
(JARA, 2020, p. 166).

Jara (2020) assim sintetiza a discussão sobre educação popular e paradigmas emancipatórios que sucedeu o debate da refundamentação:

Podemos afirmar que a primeira década deste novo século culmina com claro consenso
em torno do qual os processos de educação popular se inscrevem na perspectiva da
construção permanentemente atualizada de paradigmas emancipatórios, como horizonte
ético, desde seu próprio acumulado teórico e prático, político-pedagógico, mas em
vínculo com outras correntes de pensamento e ação (pedagogias críticas, filosofia,
teologia, psicologia da libertação, ecologia de saberes, a digna fúria zapatista ou o bem
viver de tradição andina entre outros). (JARA, 2020, p. 172).

Em 2012, durante a realização da VIII Assembleia realizada em Lima (Peru), o CEAAL tomou a decisão de mudar o nome de "Conselho de Educação de Adultos da América Latina" para "Conselho de Educação Popular da América Latina e do Caribe", devido à sua diversidade tanto em relação às práticas bem como aos espaços onde tais práticas se realizavam (governamentais, não governamentais, formais, não formais, institucionais ou incentivados pelas organizações e grupos da sociedade civil). Nesse sentido, a natureza do CEAAL como movimento de educadores e educadoras populares da América Latina e Caribe se consolidou a partir das resoluções da Assembleia Intermediária realizada em 2014 em Quito (Equador) sob o tema: "Construindo Movimento de Educação Popular". Esse posicionamento expressa não só uma maior articulação do CEAAL com os movimentos sociais, mas também como movimento que aposta e luta por uma Educação Popular transformadora em todos os espaços e que busca reunir os educadores e as educadoras que neles atuam. Nesse processo, ampliam-se as alianças e as articulações com as Universidades e os espaços de natureza mais acadêmica, como, por exemplo, a ativa participação do CEAAL na Conselho Latino-americano de Ciências Sociais (CLACSO), por meio do Grupo de Trabalho de Educação Popular e Pedagogias Críticas.

No XII Fórum Social Mundial, realizado em fevereiro de 2018, em Salvador (Bahia, Brasil), sob o lema "Resistir é criar, resistir é transformar", o CEAAL realizou cinco atividades e apresentou, ao final, uma Declaração à Assembleia Mundial dos Povos, por meio da qual analisou os projetos de sociedade e as concepções de educação em disputa na sociedade. Ao final, o CEALL propôs:

Acreditamos na importância de impulsionar múltiplos processos de formação política desde as bases e os territórios e as culturas populares, que respondam à diversidade de problemáticas e necessidades particulares no marco de um paradigma de transformação global. "Um outro mundo possível" não deve ser somente uma voz de ordem, deve ser uma prática cotidiana que possibilite a construção em todos os campos da vida, relações democráticas, justas, equitativas e solidárias, entre todas as pessoas e todos os povos.

Práxis Educativa, Ponta Grossa, v. 16, e2116623, p. 1-20, 2021

Disponível em: <https://www.revistas2.uepg.br/index.php/praxiseducativa > 
A atualidade do pensamento de Paulo Freire para reinventar as práticas de formação política no âmbito...

Desde essa prática cotidiana vamos construir os alicerces de essa outra maneira de viver para o futuro da humanidade. (CEAAL, 2018, n.p.).

O CEAAL, com 37 anos de existência, atualmente se constitui como um movimento de educadores e educadoras populares, composto por cerca de 140 organizações/movimentos/coletivos/pessoas e está presente em 21 países da América Latina e Caribe. Suas prioridades temáticas são: formação política; cultura; comunicação popular; paz e direitos humanos; feminismo e luta antipatriarcal; economia solidária; incidência em políticas educativas, sobretudo nas de Educação de Jovens e Adultos.

Oscar Jara, que, hoje, ocupa a presidência do CEAAL, escreveu um texto ${ }^{2}$, no qual ele constrói uma discussão em torno do Livro "Pedagogia da Autonomia" para refletir sobre a íntima relação entre ser sujeito do processo de transformação social e sujeito de processos educativos criadores, expresso no trecho: "Se nos formamos como pessoas críticas e criativas, isso se expressará em formas de participação social críticas criativas" (JARA, 2020, p. 3). O autor aponta também que, segundo Freire (1995, p. 25 apud JARA, 2020, p. 3): "Ensenar no es transferir conocimientos, sino crearlas condiciones para suproducción o construcción" em sua totalidade, pois, de acordo com Jara (2020), o processo educativo implica criar condições para produzir e construir conhecimentos transformadores. Tal produção e criação tem de possibilitar um processo de aprendizagem, de reflexão crítica, para criar uma capacidade de análise, de comunicação, de sensibilização de problemas para poder trabalhar e compreender o que acontece ao nosso redor.

\section{Caminhos metodológicos, análise e discussão}

Nesta seção, buscamos sistematizar nossa discussão de forma a ressaltar como o histórico do CEAAL nos direcionou para a identificação das categorias freirianas presentes no cenário construído pelo/no Conselho ao longo da sua existência e atuação. Como já apontamos, essa identificação foi feita a partir do cotejamento de uma seleção preliminar de palavras com os verbetes do Dicionário Paulo Freire (STRECK; REDIN; ZITKOSKI, 2010), que reúne, a partir de uma pesquisa minuciosa, uma análise de 232 verbetes apresentados na forma de categorias.

Ressaltamos que a escolha do referido dicionário se deveu ao fato de que não se trata puramente de uma sequência de verbetes, mas, sim, de um conjunto de textos associados a cada um em forma de comentários escritos por diversos estudiosos do universo freiriano. Além disso, o Dicionário Paulo Freire (STRECK; REDIN; ZITKOSKI, 2010) foi traduzido para o espanhol pelo CEAAL, sendo uma obra de livre circulação entre os membros do Conselho. Segundo Streck, Redin e Zitkoski (2010), a escolha dos verbetes teve como principal referência o papel desempenhado pela palavra/expressão/pelo conceito para compreensão das diversas obras de Freire e a recorrência de seus usos pelo autor.

Motivados pelo uso do dicionário e pelo contexto semântico ao qual ele nos remete, iniciamos nossa análise pela contagem de palavras nos textos seguintes coletivos: i) Assembleia dos Povos e ii) 15 Linhas de Trabalho para uma Estratégia de Formação Política do CEAAL, citados no relato do histórico do CEAAL, na seção anterior. Tal contagem foi feita pelo software Voyant-Tools, disponível na rede de internet. Esse software foi desenvolvido por dois professores canadenses e destina-se a auxiliar pesquisas nas áreas de Ciências Humanas e Sociais na análise de um ou mais textos simultaneamente, a fim de fornecer listas de frequência de palavras, gráficos de distribuição de frequência entre outros mecanismos de análise utilizadas em metodologias léxicas e semânticas.

\footnotetext{
2 ¿De qué tipo de educación hablamos cuando hablamos de una Educación "Popular"?. Disponível em: https://bit.ly/33Uz244. Acesso em: 15 maio 2021.
}

Práxis Educativa, Ponta Grossa, v. 16, e2116623, p. 1-20, 2021

Disponível em: < https://www.revistas2.uepg.br/index.php/praxiseducativa> 
A versão atual do Voyant-Tools coleta as 59 palavras mais relevantes, considerando a recorrência de aparição e a distribuição dessas palavras ao longo do texto, critério que não consideramos devido ao fato de alguns textos serem curtos, com um número reduzido de páginas para que esse critério se tornasse importante.

Para reforçar a ideia de que esses textos são resultados de um vivenciar Paulo Freire e sua obra, estendemos o uso do código Voyant-Tools a três obras de Paulo Freire - Pedagogia do oprimido, Pedagogia da autonomia e Pedagogia da esperança e, também, a textos de Jorge Osório (2020), Oscar Jara (2020) e Carlos Brandão (2012). Nosso objetivo é somente mostrar como as palavras encontradas nos documentos coletivos do CEAAL possuem uma forte relação com aqueles textos e fazer um resumo visual do contexto atual do CEAAL cofundado por diversos membros que conviveram com Paulo Freire, primeiro presidente do CEAAL, e recontam a história do conselho e da educação popular com base em suas próprias pesquisas e, também, nas recordações que possuem desse convívio. Tais relações são sistematizadas no Quadro 1. Na primeira coluna, são listadas as obras trabalhadas nesta pesquisa, enquanto na coluna 2 são relacionados os conjuntos de palavras mais relevantes fornecidas pelo Voyant-Tools - os números entre parêntesis correspondem à frequência de aparecimento de cada palavra. Destacamos, em cinza, as duas últimas células do Quadro 1 para lembrar que esses são os textos que serviram de base para a nossa busca pelas categorias freirianas.

Quadro 1 - Sistematização das obras de Paulo Freire

\begin{tabular}{|c|c|}
\hline Texto & Conjunto de palavras \\
\hline $\begin{array}{l}\text { Pedagogia do } \\
\text { oprimido }\end{array}$ & $\begin{array}{l}\text { educación* (29); popular (24); paradigma (7); democrática (6); práctica (6); sujetos (6); } \\
\text { participación (5); relaciones (5); social (5); formación (4); política (4); autoritarias (3); } \\
\text { democráticas (3); gente (3); historia (3); mundo (3) }\end{array}$ \\
\hline $\begin{array}{l}\text { Pedagogia da } \\
\text { autonomia }\end{array}$ & $\begin{array}{l}\text { ensinar (163); mundo (128); professor (115); saber (94); curiosidade (85); ética (80); educando } \\
\text { (74); liberdade (70); pensar (67); certo (63); educação (54); docente (51); autoridade (50); } \\
\text { educador (48); discurso (47); educandos (47); experiência (46); objeto (46); crítica (41); homens } \\
\text { (40); sujeito (40); conhecimento (38); gente (38); política (38); humano (37); autonomia (36); } \\
\text { educativa (36); história (35) aprender (34); mulheres (34); direito (33); tempo (33); luta (32); } \\
\text { realidade (32) }\end{array}$ \\
\hline $\begin{array}{l}\text { Pedagogia da } \\
\text { esperança }\end{array}$ & $\begin{array}{l}\text { mundo (210); pedagogia (166); educação (163); prática (138); oprimido (124); luta (120); tempo } \\
\text { (112); discurso (94); leitura (93); experiência (89); escola (87); esperança (86); saber (85); } \\
\text { política (83); história (81); educador (77); professor (71); classe (69); sociais (62); populares } \\
\text { (61); educandos (60); trabalhadores (60); linguagem (59); realidade (58); sociedade (56); } \\
\text { conhecimento (55) }\end{array}$ \\
\hline $\begin{array}{l}\text { Texto de } \\
\text { Osório }\end{array}$ & $\begin{array}{l}\text { popular (44); educación (33); movimientos (30); social (14) e sociales (24); política (23); } \\
\text { pedagogía (20); cultura (14) e culturales (12); conocimiento (13); escuela (13); práctica (12); } \\
\text { teoría (12); educadores (11); investigación (11); políticas (11) e políticos (9); saberes (10); } \\
\text { educativa (7); liberación (7); movimiento (7); mundo (7); pedagógicas (7) }\end{array}$ \\
\hline $\begin{array}{l}\text { Texto de } \\
\text { Carlos Brandão }\end{array}$ & $\begin{array}{l}\text { educação (81) e educar (5); pedagogia (16); social (16) e sociais (11); oprimido (11); territórios } \\
\text { (11); diferentes (10); educadores (10); saberes (10); sociedade (10); vocação (10) e vocações (8); } \\
\text { escola (9); populares (9); saber (9); cultural (8) e cultura (6); ação (7); coletivos (7); estado (7); } \\
\text { tempos (7); ações (6); escolas (6); formação (6); história (6); prática (6); realidade (6); classe (5); } \\
\text { mundo (5) }\end{array}$ \\
\hline $\begin{array}{l}\text { Texto de Oscar } \\
\text { Jara }\end{array}$ & $\begin{array}{l}\text { educación (29); popular (24); paradigma (7); democrática (6); práctica (6); sujetos (6); } \\
\text { participación (5); relaciones (5); social (5); formación (4); política (4); autoritarias (3); } \\
\text { democráticas (3); gente (3); história (3); mundo (3) }\end{array}$ \\
\hline $\begin{array}{l}\text { "Assemblea de } \\
\text { los Pueblos" }\end{array}$ & $\begin{array}{l}\text { educação (7); popular (3) e populares (2); prática (3); social (3); atividades (2); histórico (2); } \\
\text { mundo (2); neoliberal (2); político (2); povos (2); transformação (2); autonomia (1); autoritária } \\
\text { (1); coerência (1); contexto (1); cultural (1); democrática (1); dialógica (1) }\end{array}$ \\
\hline
\end{tabular}

Práxis Educativa, Ponta Grossa, v. 16, e2116623, p. 1-20, 2021

Disponível em: < https://www.revistas2.uepg.br/index.php/praxiseducativa $>$ 
A atualidade do pensamento de Paulo Freire para reinventar as práticas de formação política no âmbito...

\begin{tabular}{|c|c|}
\hline Texto & Conjunto de palavras \\
\hline $\begin{array}{l}\text { "15 Lineas de } \\
\text { Trabajo..." }\end{array}$ & $\begin{array}{l}\text { formación (22); popular (22); política (19), político (7) e políticas (5); educación (18); sociales } \\
\text { (11) e social (5); identidad (6); colectivos (5); estratégia (5); organizaciones (5); acción (4); } \\
\text { cultural (4); dinámicas (4); diversidad (4); diálogos (2) emancipatório (1) }\end{array}$ \\
\hline
\end{tabular}

Fonte: Elaborado pelos autores com base no conjunto de palavras fornecidas pelo Voyant-Tools.

* As palavras que estão em espanhol no quadro seguem o idioma em que foram publicadas.

A fim de especificarmos ainda mais nosso recorte, não consideramos os verbetes relacionados à educação popular e formação e suas respectivas versões em espanhol por se constituírem em nosso objeto de pesquisa. Além disso, as palavras "social" e "sociais" e suas respectivas versões em espanhol não foram consideradas por aparecerem no dicionário de forma complementar de um verbete, como, por exemplo, luta social.

Por fim, o conjunto final de palavras foi obtido pensando o contexto da Formação Política na Educação Popular a partir das seguintes considerações:

1. A formação política implica necessariamente em política, que adquire um caráter dinâmico com a ideia de politicidade.

2. A política/politicidade carece de diálogo e dialogicidade.

3. O diálogo/dialogicidade implica uma relação horizontal entre os envolvidos que devem ter autonomia para atuar e emancipação diante do mundo.

4. A autonomia/emancipação deve garantir a práxis.

5. A práxis deve ser exercida considerando todos os saberes envolvidos, toda a bagagem cultural de educadores, educadoras e educandos.

6. Finalmente, para que esses elementos se harmonizem, trazemos uma fala da apresentação do Dicionário Paulo Freire (STRECK; RENDIM; ZITKOSKI, 2010) cuja motivação, segundo os organizadores, foi "[...] apreender algumas dessas palavras vivas, travar com elas um diálogo e devolvê-las ao público para que continuem a sua trajetória humanizadora" (STRECK; RENDIM; ZITKOSKI, 2010, p. 13), e "[...] fazer um exercício do pensar certo na perspectiva de uma reflexão rigorosa e metódica" (STRECK; RENDIM; ZITKOSKI, 2010 , p. 13). Com essa reflexão em mente, incluímos a categoria "pensar certo", pois entendemos que ela atua como uma amalgama do conjunto das categorias da obra de Paulo Freire.

Com esse raciocínio definimos as categorias que serão exploradas neste estudo, a saber: política/politicidade, cultura, autonomia/emancipação, práxis, diálogo/dialogicidade e pensar certo. Justificamos a não utilização de algumas das categorias que constam nos conjuntos apresentados no Quadro 1 por sua forte relação com aquelas escolhidas. Por exemplo, as categorias contexto, diversidade, movimento, liberdade estão associadas à cultura; enquanto prática, atividade, ação, dinâmica e transformação estão implicitamente inseridas em práxis. Consideramos também que as categorias autoritarismo, movimento, organização são naturalmente utilizadas nas narrativas relativas a diálogo/dialogicidade e autonomia/emancipação. As categorias selecionadas serão discutidas a seguir considerando alguns aspectos apresentados no Dicionário Paulo Freire e nossa análise com vistas à Formação Política na Educação Popular no âmbito do CEAAL.

\section{Política/politicidade}

A palavra "política" é amplamente citada por Paulo Freire em sua obra. Segundo o glossário Conceitos de Educação em Paulo Freire (VASCONCELOS; BRITO, 2012), essa palavra aparece sozinha e, também, adjetivando substantivos como natureza, relação, nitidez, práxis entre outros, nas obras

Práxis Educativa, Ponta Grossa, v. 16, e2116623, p. 1-20, 2021

Disponível em: <https://www.revistas2.uepg.br/index.php/praxiseducativa> 
Alfabetização: leitura de mundo, Leitura da palavra, Pedagogia da esperança, Pedagogia da autonomia, além de ser tratada em diversos artigos e entrevistas. No texto intitulado Educação é um ato político, que consiste em uma entrevista ao Cadernos de Ciências e Educação (FREIRE, 1991), Paulo Freire reitera que essa afirmação não implica que a educação seja um ato partidário, mas, sim, que a prática educativa não pode ser indiferente a valores e ao projeto de sociedade na qual ela está inserida.

A intensidade da ideia de política assume uma natureza de conceito na obra freiriana e é discutida por Costa (2010) em forma do verbete "Política" e, em seguida, "Politicidade", no Dicionário Paulo Freire (STRECK; REDIN; ZITKOSKI, 2010). A autora defende que, ao considerar o inacabamento como "a diferença profunda entre o ser condicionado e o determinado" (COSTA, 2010, p. 531), Freire explica em que reside nossa condição política, e tal condição não é e nem pode ser de neutralidade. Segundo a autora, a educação é um ato político, porque está a serviço de uns e não de outros. Assim sendo, a opção por uma educação progressista reconhece-a como não neutra, com forte compromisso com as classes populares, no reconhecimento do seu lugar histórico e na busca permanente de ser mais. Costa (2010) conclui o verbete dizendo: "A educação como ato político compreende a existência de vários projetos que estão em disputa na sociedade, bem como a defesa que fazemos na defesa de um, e não de outro. Reconhece também o diálogo como consequente dimensão do direito de dizer a palavra e do respeito ao outro" (COSTA, 2010, p. 532).

Os projetos de educação em disputa podem ser resumidos entre projetos hegemônicos, que objetivam a manutenção formativa de uma elite, acentuando cada vez mais as diferenças sociais na óptica do mercado e da competitividade, contra uma educação pública, democrática, laica, crítica e que busque no respeito às diversidades ser uma educação para todos. Além disso, nos últimos tempos, assistimos a mais uma corrente que buscou na neutralidade uma justificativa para defender um projeto que se anunciava como uma educação não política e contra qualquer tipo de ideologia. Trata-se da chamada "Escola sem Partido", que é uma articulação de forças conservadoras e de extrema direita para tentar impor um controle ideológico em relação às práticas de uma educação crítica nas escolas e aos educadores(as) responsáveis por essas práticas, bem como impedir a introdução de programas sobre gênero, liberdade de orientação sexual e religiosa nas escolas.

A politicidade é característica de uma prática educativa progressista e exige uma leitura do mundo. Freire recordava com muita insistência que a neutralidade é impossível no ato educativo, fazendo um contraponto necessário à tentativa da ideologia neoliberal, sobretudo nos anos de 1990, de despolitizar a sociedade e o debate de ideias.

Costa (2010) assim sintetiza a visão freiriana acerca da politicidade:

$\mathrm{O}$ ato da politicidade requer nossa assunção ao engajamento, sabendo-nos comprometidos com outro mundo possível, para potencializarmos e protagonizarmos cada vez mais quefazeres articulados por meio da participação e da democracia, na direção de uma vida mais bonita para todos e todas, pois é a partir desses pressupostos que romperemos com o fatalismo desesperançoso que pauta a sociedade capitalista e o de construir imperialista de nossa época. (COSTA, 2010, p. 534).

Em Freire (2000), a politicidade é característica da prática educativa e está em estreita articulação à proposta de mudança social, de forma que uma prática pedagógica progressista precisa afirmar que "mudar é difícil, mas é possível" Nessa perspectiva, trata-se de explicitar que tipo de educação é necessária para alcançarmos o objetivo de construir um país com um desenvolvimento integral, inclusivo, equitativo e sustentável, por meio do exercício de uma cidadania ativa e da ampliação das práticas da democracia participativa.

Práxis Educativa, Ponta Grossa, v. 16, e2116623, p. 1-20, 2021

Disponível em: <https://www.revistas2.uepg.br/index.php/praxiseducativa > 
A atualidade do pensamento de Paulo Freire para reinventar as práticas de formação política no âmbito...

Freire (2000) afirma que a educação é ato político, o que implica uma crítica a todo tipo de visão autoritária, determinista, alienada e a-política de mundo. Assim sendo, podemos dizer que, se, de um lado, isso reforça a importância dos processos de formação política; de outro, advertenos sobre os riscos de metodologias autoritárias e ou explicações deterministas serem reproduzidas na sua prática. Por isso, a dialogicidade, a compreensão da História como possibilidades, bem como a problematização da realidade são antídotos da pedagogia freiriana aos riscos acima apontados.

Assim, a politicidade, nos termos propostos por Freire (1992), coloca como desafio para os processos de formação política hoje uma adequada leitura do contexto histórico que estamos vivendo para dela extrair as questões geradoras que orientarão o projeto político-pedagógico a ser desenvolvido. Nesse sentido, tal projeto deve ter uma clara opção por uma educação crítica e progressista, mas ao mesmo tempo não dogmática, no qual a busca permanente, a abertura à mudança e o saber mover-se em um contexto de incertezas sejam um exercício contínuo.

\title{
Cultura
}

A cultura é categoria central no pensamento de Freire, pois refere-se a uma criação do próprio ser humano por intermédio do trabalho transformador sobre a natureza. Brandão (2010), ao escrever o texto do verbete sobre cultura (movimentos de cultura popular) para o Dicionário Paulo Freire, explicita o sentido mais geral da cultura para Freire:

\begin{abstract}
Assim, vivemos e interagimos na e através da cultura objetivamente criada por nós. E somos subjetivamente a interiorização de práticas culturais do fazer, de regras do agir (as diferentes gramáticas sociais), de sistemas de significação da vida e do mundo em que vivemos (as ideologias, as teorias e os sistemas mais abrangentes de saber e de sentido). Os movimentos de cultura popular trouxeram para o campo da educação a cultura como conceito, ideia, valor e fundamento de ações sociais, inclusive pedagógicas. Dito de outro modo: ao lado de outras práticas sociais do pensar e do fazer, como as artes, as ciências, as filosofias, as tecnologias do agir e do cuidar (como a engenharia, a medicina, a culinária) eles situaram a educação no interior da cultura. (BRANDÃO, 2010, p. 171).
\end{abstract}

Freire (1981) afirma que o fazer cultura sempre esteve associado à expressão de atitude "crítica" diante dos desafios do seu tempo e que, por meio de atitude permanente de reflexão-ação, podemos passar da "consciência ingênua" a uma consciência "crítica". Brandão (2010) assim sintetiza a importância do pensamento de Freire e dos movimentos de cultura popular na afirmação da dimensão política da cultura e da educação: "Como um dos principais pensadores dos movimentos de cultura popular e da pedagogia crítica situada em uma proposta de educação libertadora, Paulo Freire foi sempre um defensor da ideia de que existe uma dimensão política na cultura e, portanto, na educação" (BRANDÃO, 2010, p. 172).

Ao analisar a questão da cultura na dinâmica real da história, Brandão (2010) ajuda-nos a compreender o lugar da cultura popular:

A oposição estrutural entre modos sociais de participação na cultura é o que explica a cultura popular. No contexto das sociedades latino-americanas, por exemplo, esta é uma das faces da relação negada de universalização da cultura, e torna mais do que visíveis a posição subalterna de saberes, valores e símbolos de sujeitos e grupos étnicos e sociais dominados no processo da história. Assim, as culturas dos dominados são, ao mesmo tempo, a cultura imposta às classes populares, e as culturas que elas criam, de acordo com a forma como participam na vida social em todas as suas dimensões. (BRANDÃO, 2010, p. 178).

Brandão (2010, p. 181) alerta-nos que, para Freire, há uma “invasão cultural erudito/dominante" sobre a cultura popular em sociedades desiguais e fundadas na oposição entre

Práxis Educativa, Ponta Grossa, v. 16, e2116623, p. 1-20, 2021

Disponível em: <https://www.revistas2.uepg.br/index.php/praxiseducativa> 
classes sociais. Em sentido inverso, um projeto de superação das desigualdades, das injustiças, das exclusões das comunidades populares deveria possuir uma indispensável dimensão cultural. Do ponto de vista educativo, a invasão cultural expressa-se em práticas que Freire (2006) denominou de "extensão", a qual ele contrapõe a "comunicação" capaz de promover uma "educação dialógica para uma ação transformadora".

Brandão (2010) assim se refere à visão de Paulo Freire acerca do lugar específico da cultura na luta política:

Segundo Paulo Freire, há um espaço concreto de luta política que se realiza no domínio da cultura. Uma luta popular que agindo através da própria cultura participa da criação de sua própria liberdade. A cultura alienada é o solo onde floresce no oprimido a consciência alienada. Esta consciência é o nevoeiro que impede ver a dominação tal como ela existe. Que o impede de compreender sob que condições existe e, portanto, aprisiona uma ação política contra ela, tal como seria necessário e correto fazê-la. (BRANDÃO, 2010, p. 181).

Ainda segundo Brandão (2010), na perspectiva de Paulo Freire, os "Círculos de Cultura" são o lugar onde se encontra uma educação libertadora com uma cultura popular em uma "ação cultural para a liberdade". Essa prática político-pedagógica a partir das ações culturais deveria partir do resgate dos saberes populares, da arte popular, das diferentes tradições e dos costumes, refletidas na sua experiência de vida em interação com os agentes/educadores que vinham dos movimentos de cultura popular. Nas décadas que se seguiram a essa experiência, do início dos anos de 1960, a proposta dos Círculos de Cultura foi aplicada de maneiras muito diferenciadas, tanto em atividades educativas dentro e fora da escola, quanto em atividades culturais e atividades políticas.

Uma das expressões mais recentes dessa proposta da cultura como ação libertadora foi a proposta dos Pontos de Cultura que se constituem em espaços pedagógicos em que, por meio de diferentes formas de linguagens e arte, diferentes atores sociais historicamente excluídos e silenciados, há a possibilidade de expressar sua percepção dos problemas vividos no cotidiano e de propor ações de transformação da realidade social. Particularmente entre as juventudes periféricas, os slams, o rap, o hiph-hop têm sido algumas das linguagens utilizadas em trabalhos de educação popular para formação de uma consciência crítica na perspectiva de uma ação transformadora.

As iniciativas de construir uma proposta de Educação Integral para as redes públicas de ensino a partir de práticas instituídas no contraturno da escola tem tido também na cultura e nas expressões artísticas o seu eixo central de estruturação. A concepção dos "territórios educativos", que parte do princípio de que a escola deve se articular com outros atores sociais do território onde está situada, reconhece, nas diferentes expressões artísticas e culturais existentes, um potencial educativo de extrema importância.

\section{Autonomia/Emancipação}

A autonomia é um conceito fundamental na obra de Paulo Freire a ponto de servir de título para seu livro Pedagogia da autonomia; saberes necessários à prática educativa, dirigido a educadoras e educadores, no qual ele faz uma síntese dos saberes necessários à sua formação como sujeitos autônomos. Machado (2010) ressalta que autonomia no contexto da obra freiriana é um processo de decisão e de humanização que vamos construindo historicamente, a partir de inúmeras e variadas decisões que vamos tomando, ao longo de nossa existência. Assim, uma pedagogia da autonomia precisa estar centrada em práticas estimuladoras da participação, da decisão, da corresponsabilidade por parte de todos os atores envolvidos no processo educativo.

Práxis Educativa, Ponta Grossa, v. 16, e2116623, p. 1-20, 2021

Disponível em: <https://www.revistas2.uepg.br/index.php/praxiseducativa > 
A atualidade do pensamento de Paulo Freire para reinventar as práticas de formação política no âmbito...

A construção da autonomia individual e coletiva liga-se diretamente à questão da liberdade e da democracia tendo na pedagogia libertadora uma mediação fundamental. Enquanto no ideário neoliberal a noção de autonomia vem associada ao estímulo do individualismo e da competitividade, em Freire, ela está associada à solidariedade como compromisso histórico entre homens e mulheres, a uma ética universal do ser humano e a participação cidadã.

Já a emancipação humana aparece na obra de Freire como una grande conquista política a ser efetivada pela práxis humana e é colocada como um grande projeto de libertação social. Moreira (2010), ao escrever o texto do verbete sobre emancipação, assim sintetiza o seu sentido na obra de Paulo Freire: "A emancipação humana aparece, na obra de Paulo Freire, como uma grande conquista política a ser efetivada pela práxis humana, na luta ininterrupta a favor da libertação de pessoas de suas vidas desumanizadas pela opressão e dominação social" (MOREIRA, 2010, p. 246). Neste momento, cabe dizermos que a emancipação humana assim concebida coloca a luta política e a prática pedagógica na perspectiva de um processo permanente de busca, o que se diferencia claramente de visões dogmáticas e mecanicistas sobre etapas da transformação ou determinismos históricos.

O projeto de emancipação defendido por Freire abarca o multiculturalismo em que o direito de ser diferente como conquista de cada cultura em uma sociedade democrática deve envolver o diálogo crítico entre diversas culturas como forma de ampliar e consolidar a emancipação humana (MOREIRA, 2010, p. 182). Nessa perspectiva, as práticas de educação popular vêm buscando promover uma pedagogia da interculturalidade em função da afirmação crescente na cena pública das diversas identidades étnico-raciais e religiosas que foram sistematicamente excluídas e discriminadas pelo colonialismo e autoritarismo dominantes na história do continente latino-americano. Também a intensidade e a complexidade crescentes do fenômeno das migrações apontam no mesmo sentido da necessidade de valorização dos seus saberes e de garantia dos seus direitos educativos na perspectiva da interculturalidade.

\section{Práxis}

Práxis é um conceito que atravessa toda a obra de Paulo Freire e é a base epistemológica da sua pedagogia libertadora. Rossato (2010), ao escrever o verbete "práxis" para o Dicionário Paulo Freire, assim sintetiza o conceito:

Práxis pode ser compreendida como a estreita relação que se estabelece entre um modo de interpretar a realidade e a vida e a consequente prática que decorre desta compreensão, levando a uma ação transformadora. Opõe-se às ideias de alienação e domesticação, gerando um processo de atuação consciente que conduza um discurso sobre a realidade para modificar esta mesma realidade. É uma síntese entre teoria-palavra-ação. (ROSSANO, 2010, p. 538).

$\mathrm{Na}$ perspectiva da práxis, buscamos a superação da tradicional dicotomia entre teoria e prática. Ao utilizar o método dialético, Freire (1987) afirma a unidade entre o pensar e o agir e o pensar e o ser; e, ao partir da unidade entre teoria e prática, Freire (1987) sustenta que o processo educativo sempre deve partir da prática social e a ela regressar para uma ação transformadora.

A educação popular tem buscado centralizar suas ações, atividades e atuações na dinâmica da prática-teoria-prática e da ação reflexão-ação. Busca-se, assim, uma dinâmica de transformação, inclusão, valorização de saberes, conscientização do papel no mundo e visão crítica da realidade dos atores envolvidos nos processos de educação popular.

Práxis Educativa, Ponta Grossa, v. 16, e2116623, p. 1-20, 2021

Disponível em: < https://www.revistas2.uepg.br/index.php/praxiseducativa> 
Na metodologia da práxis, o ponto de partida é a prática; e o ponto de chegada, uma nova prática como ação transformadora. Por essa razão, o método dialético é aquele mais coerente, pois permite partir da "prática social" dos participantes e não da teoria abstrata. Na perspectiva da práxis, o conhecimento é sempre construção social, histórica e coletiva; e a realidade é una, múltipla, complexa, dinâmica, contraditória, enfim é uma realidade totalizadora. Por isso, a metodologia da práxis aproxima-se do paradigma da complexidade e da abordagem da "transdisciplinaridade" no desenho de programas educativos. Nesse enfoque, rompem-se as lógicas dedutivas dos velhos paradigmas. Ao contrário, partem do particular, do específico, da realidade mais próxima. Seu método é indutivo e, assim, partem daquilo que é próprio e mais próximo, do objetivo e do subjetivo, do simples e do concreto. É a partir daí que se constrói, de modo indutivo e processual, o conhecimento novo, sempre em diálogo com a teoria já existente.

A metodologia da práxis aproximou historicamente as práticas da educação popular da pesquisa participante ou investigação-ação-participativa-IAP. As práticas de pesquisa participativa têm possibilitado uma metodologia sistemática de aproximação e leitura da realidade social dos participantes de programas educativos, com base em uma relação dialógica em que os sujeitos da pesquisa são vistos como "sentipensantes", ou seja, tomados não apenas nas suas formas de pensar, mas também no seu modo de sentir e de ser. A prática da pesquisa participante tem sido importante fonte de construção dos temas geradores dos programas de educação popular.

Assim, o desafio daqueles programas de formação política que pretendem contribuir para a construção de uma contra hegemonia popular é a utilização da metodologia da práxis libertadora na concepção freiriana, pois ela possibilita tomar a prática social como ponto de partida, promover um processo de teorização sobre a prática e regressar a ela com uma ação transformadora sobre a realidade social. Essa concepção contrapõe-se a visões autoritárias sobre o processo de construção do conhecimento e condução da luta política. A metodologia da práxis é radicalmente democrática e comprometida com a autonomia do sujeito individual e coletivo e com a emancipação humana.

\section{Diálogo/Dialogicidade}

O diálogo/dialogicidade é outra categoria fundante da proposta de educação humanizadora e libertadora de Freire. Zitkoski (2010a), ao escrever o verbete sobre diálogo/dialogicidade, aponta que, em Pedagogia do oprimido, Freire elabora uma fundamentação teórico-filosófica sobre as condições do diálogo verdadeiro e seu papel central para uma educação libertadora. Segundo Zitkoski (2010a), o diálogo freiriano em oposição a educação bancária,

[...] deve começar já "na busca do conteúdo programático", em que estão implicados saberes diferentes, que não podem ser impostos por alguém, mas podem emergir a partir da comunicação crítica e esperançosa sobre nossa condição no mundo $O$ desafio freiriano é construirmos novos saberes a partir da situação dialógica que provoca a interação e a partilha de mundos diferentes, mas que comungam do sonho e da esperança de juntos construirmos nosso ser mais. (ZITKOSKI, 2010a, p. 198-199).

O diálogo freiriano e a metodologia dialógica são elementos significativos de um processo de construção democrática. O elitismo e o autoritarismo historicamente operados pelas classes dominantes enraizaram-se profundamente na sociedade brasileira e, na atual conjuntura, uma forte onda conservadora deu expressão política a forças de extrema direita que, hoje, controlam o governo central em nosso país. Ao afirmar-se a necessidade de construirmos uma cidadania ativa e uma democracia substantiva para superarmos as múltiplas formas de opressão, estamos, portanto, nos referindo à criação de novas formas de exercício do poder ancoradas a uma cultura política radicalmente democrática. Para Freire (1993), isso só é possível a partir de um intenso e criativo trabalho político-pedagógico de natureza dialógica.

Práxis Educativa, Ponta Grossa, v. 16, e2116623, p. 1-20, 2021

Disponível em: <https://www.revistas2.uepg.br/index.php/praxiseducativa> 
A atualidade do pensamento de Paulo Freire para reinventar as práticas de formação política no âmbito...

Freire (1993) adverte-nos que uma proposta de gestão democrática da educação tem, no diálogo e no conflito, fatores inerentes ao processo e, por conseguinte, trata-se de pedagogizar os conflitos, ou seja, construir espaços de reconhecimento recíproco, de interesses distintos, mas também de negociação a partir de regras democráticas pactuadas entre os diversos atores. A dialogicidade estará na metodologia de escuta e conversa entre os atores e no estabelecimento do diálogo que seja capaz de enfrentar e propor soluções aos problemas em questão.

Os programas de formação política hoje se deparam com um grande desafio que é o de como estabelecer o diálogo com aquela parcela da população que aderiu ao conservadorismo político, a expressões de preconceito e, em alguns casos, até mesmo de ódio. Para enfrentar tal desafio na metodologia da dialogicidade, algumas virtudes das educadoras e dos educadores são fundamentais. Para Freire (1995), a dialogicidade requer atitudes de humildade e de tolerância nas relações com o outro e no reconhecimento à diferença como aspecto central de uma cultura democrática. Segundo o autor:

Tolerância e humildade são virtudes fundamentais. Na humildade eu trabalho com a hipótese de que existem outras verdades, mesmo aquelas contra as quais eu luto. Não tem nada a ver com humilhação. E sim com a tolerância não no sentido da conivência, mas no sentido de aceitar a diferença e reconhecer que só podemos crescer na diferença. (FREIRE, 1995, p. 73).

A dialogicidade requer ainda atitudes de perseverança, de autonomia, de amorosidade, de respeito à diversidade, de solidariedade, de abertura ao novo e disponibilidade à mudança, de saber conviver criativamente com as incertezas, do gosto pela alegria e pela vida, de recusa aos fatalismos e de identificação com a esperança. Assim sendo, a formação das educadoras e dos educadores é elemento central do desenho de uma estratégia de educação/formação política, sendo importante a metodologia da práxis no sentido de proporcionar um processo de formação que parta de uma reflexão da prática dos formadores e que possibilite a construção de conhecimentos que promovam uma modificação da sua prática na realidade onde atuam, no sentido de uma apropriação cada vez mais coerente da perspectiva dialógica na sua atuação educativa.

\section{Pensar certo}

O pensar certo é uma categoria que percorre toda obra de Freire, a qual acreditamos ser de grande relevância para os objetivos deste artigo. Zitkoski (2010b) assim nos introduz à importância do pensar certo para Freire:

A categoria do pensar certo na obra de Freire está situada no centro de sua pedagogia crítico-humanizadora, comprometida com a luta por um mundo mais justo, liberto e igualitário. Com esse propósito é que Freire não se cansava de falar na importância da coerência entre teoria e prática, no valor da crítica e da autocrítica para a educação problematizadora, no desafio do pensamento dialético e, acima de tudo, na radicalidade do diálogo e da humildade inerentes a uma educação autenticamente progressista. Educação esta que precisa estar sempre aberta às diferenças e ao novo na história, sem abrir mão de sua posição política a favor dos oprimidos. (ZITKOSKI, 2010b, p. 515).

Pensar certo, na perspectiva de Freire, é cultivar a humildade e o gosto por estar sempre aprendendo em comunhão e solidariedade com os outros. Enfim, pensar certo é jamais se deixar levar pela tentação da arrogância e da superioridade inibidora do estabelecimento de relações de verdadeiro diálogo e da construção de projetos amorosos e solidários (ZITKOSK, 2010b). O pensar certo tem a ver com a recusa de todos os tipos de dogmatismos como uma das exigências para uma educação crítica, com a disponibilidade de dialogar com o diferente, com a capacidade

Práxis Educativa, Ponta Grossa, v. 16, e2116623, p. 1-20, 2021

Disponível em: <https://www.revistas2.uepg.br/index.php/praxiseducativa> 
de desaprender determinadas certezas, com o pensar crítico associado ao corpo, à emoção, à curiosidade e ao desejo.

O pensar certo, em Freire, é uma categoria que articula os diversos saberes necessários a uma prática educativa progressista, é um exercício de denúncia da exclusão e da destruição promovida pela lógica neoliberal e o anúncio de que com esperança e luta é possível sonhar com outro mundo. Isso requer pensar a história não como determinismos, mas como possibilidades. Pensar certo é radical, mas não sectário. Pensar certo é a busca contínua de uma coerência éticopolítica da nossa ação como educadores e educadoras progressistas.

\section{Considerações finais}

Ao considerarmos a história da educação popular e do CEAAL, podemos constatar que seus desafios e suas transformações estão relacionados a diferentes momentos históricos vividos e a como eles impactaram, por meio das suas práticas, os sujeitos históricos. Nesse sentido, podemos afirmar que, em 2020, a pandemia e o conjunto de crises que ela tornou visíveis e aprofundou (econômica, social, política, ambiental, cultural, educacional) inauguraram um novo período na história da educação popular.

Trata-se de momento inédito pela magnitude e pela natureza dos desafios que estão colocados. Diante deles, podemos afirmar que as categorias do pensamento de Paulo Freire seguem vigentes e fornecem fundamentos éticos, políticos e pedagógicos que muito contribuem nas redefinições necessárias do papel e dos instrumentos de ação da educação popular e da formação política no atual contexto e nas prefigurações do pós-pandemia.

A primeira contribuição está exatamente em como se posicionar diante desse momento histórico inédito. A recusa em Freire de qualquer posição fatalista e determinista diante da história e a sua afirmação da história como "tempo de possibilidades" já nos posiciona em uma perspectiva ético-política transformadora diante desse momento de crise.

Uma segunda contribuição tem a ver com a compreensão de que, a partir de uma práxis libertadora, estão se construindo, em muitos e diversos territórios, práticas alternativas inspiradas pelo cuidado com a vida e por uma democracia radical, que vão criando o que Freire denominou de "inéditos viáveis", como sendo concretizações, das mais diversas, de "sonhos possíveis". Tais práticas vão se tecendo como redes, criando sinergias, mas ainda sem a força e articulação suficientes para contrapor-se ao domínio hegemônico do capitalismo neoliberal, do autoritarismo, do patriarcado, do racismo estrutural.

A construção de uma contra-hegemonia popular requer, e vai aí uma terceira contribuição, uma educação libertadora, crítica e dialógica com claro posicionamento em favor dos oprimidos e dos excluídos historicamente na sociedade latino-americana. Essa educação está na contramão da educação "bancária" fundada em princípios autoritários, em relações verticalizadas e na prática da mera transferência de conhecimentos. Uma educação crítica e dialógica promove um processo de problematização da realidade social a partir de práticas horizontais e de troca de saberes, visando o engajamento social em uma ação transformadora.

Nesse viés, a ênfase no aprendizado das práticas de decisão no processo de construção da autonomia individual e coletiva parece-nos o elemento central para a radicalização da democracia e das práticas de gestão democrática na educação. É nesse sentido que os próprios processos formativos precisam envolver momentos de escolhas e decisões como aprendizado importante para uma autonomização do educando no seu próprio itinerário formativo. No tocante à

Práxis Educativa, Ponta Grossa, v. 16, e2116623, p. 1-20, 2021 
A atualidade do pensamento de Paulo Freire para reinventar as práticas de formação política no âmbito...

emancipação humana, ela aparece no horizonte possível das transformações que pretendemos como nosso projeto de uma sociedade fundada no cuidado com a vida, na solidariedade e na democracia radical e participativa.

Com relação à cultura, Freire fez, lá nos anos de 1960, o importante reconhecimento da dimensão política da cultura e da educação e do papel de ambas em um projeto de País. Vivemos hoje momento histórico em que forças conservadoras e de extrema direita buscam travar uma disputa política ideológica na sociedade, em busca de justamente esvaziar o sentido político da educação e da cultura, elegendo Paulo Freire como um de seus alvos prioritários de ataque. As práticas de educação popular na perspectiva da resistência voltam a estar profundamente articuladas aos movimentos culturais de resistência, pois permitem a livre expressão de subjetividades críticas e a afirmação de identidades dos sujeitos. A defesa do legado de Paulo Freire tem sido, também, importante instrumento político pedagógico de reflexão sobre práticas em educação popular e não só de difusão do seu pensamento, mas também de sua recriação à luz dos novos desafios que o contexto trazido com a pandemia vem evidenciando e projetando.

O "pensar certo", neste momento, significa reconhecer que há dois grandes projetos em disputa na sociedade e, portanto, com suas expressões na política e na educação, tendo, de um lado, o projeto hegemônico centrado no mercado, no lucro, no individualismo, nas desigualdades, nas discriminações, no autoritarismo, na destruição da natureza; e, de outro, um projeto contrahegemônico centrado no cuidado pela vida, na solidariedade, na justiça social e equidade, na democracia radical, no respeito às diferenças e na democracia ecossocial.

Assim, pensando na oportunidade aberta neste momento de crise para uma discussão de redefinição do papel da escola, da sua relação com os diferentes atores que nela interagem, da sua relação com a comunidade e com o território, bem como com as metodologias utilizadas, uma prática educativa progressista precisa construir, dialógica e participativamente, propostas alternativas na perspectiva de uma escola crítica, transformadora e de uma educação para uma cidadania ativa e uma democracia radical. No que se refere à formação política, o "pensar certo" é um desafio para que ela se constitua em uma perspectiva emancipatória, segundo os princípios da práxis pedagógica libertadora. Uma formação que busque sempre uma adequada leitura do contexto e os respectivos temas geradores, a fim de problematizar a realidade, promover discussões na lógica dos "Círculos de Cultura" e da ética da solidariedade e comunhão entre todos. Nessa perspectiva, estamos nos referindo a uma formação política crítica e dialógica que recusa dogmatismos, determinismos e práticas autoritárias. Sua prática requer a convicção da história como tempo de possibilidades e o exercício das virtudes da humildade, da tolerância, da abertura ao novo, da criatividade, da amorosidade, entre outras.

Para concluirmos, acreditamos que as seis categorias do pensamento de Freire analisadas neste artigo podem contribuir para uma reflexão crítica dos processos de educação formação/política no período pós-pandemia, sem deixar de ter em mente, como sempre nos alertava o próprio Paulo Freire, que é preciso colocar seu pensamento em diálogo com outros no campo das pedagogias críticas e de outras áreas das ciências e da filosofia, para construirmos novos paradigmas capazes de dar conta de um mundo cada vez mais complexo e cheio de incertezas.

\section{Referências}

BRANDÃO, C. R. Cultura. In: STRECK, D.; REDIN, E.; ZITOSKI, J. J. (org.). Dicionário Paulo Freire. Belo Horizonte: Autêntica, 2010. p. 171-172. 
BRANDÃO, C. R. Paulo Freire: a Educação, a Cultura e a Universidade - memória de uma história de cinquenta anos atrás. Campinas: textos e artigos de livre circulação publicados em www.apartilhadavida.com.br, 2012.

CEAAL. Conselho de Educação Popular da América Latina e do Caribe. Fórum Social Mundial. 2018. Disponível em: https://wsf2018.org/atividades/conferencia-era-do-capital-improdutivo-ofsm-2018-e-ampliacao-das-resistencias/. Acesso em: 11 maio 2020.

COSTA, D. Política. In: STRECK, D.; REDIN, E.; ZITOSKI, J. J. (org.). Dicionário Paulo Freire. Belo Horizonte: Autêntica, 2010. p. 531-533.

FERREIRA, A. B. H. Novo Aurélio XXI: o dicionário da língua portuguesa. Rio de Janeiro: Nova Fronteira, 1999.

FREIRE, P. A educação como prática da liberdade. Rio de Janeiro: Paz e Terra, 1981.

FREIRE, P. A importância do ato de ler: três artigos que se completam. São Paulo: Cortez Editora, 1987.

FREIRE, P. A educação é um ato político. Cadernos de Ciência, Brasília, n. 24, p. 21-22, jul./set. 1991. Disponível em: http://acervo.paulofreire.org:8080/xmlui/handle/7891/1357. Acesso em: 15 maio 2021.

FREIRE, P. Pedagogia do oprimido. São Paulo: Paz e Terra, 1993.

FREIRE, P. À sombra desta mangueira. São Paulo: Olho d'água, 1995.

FREIRE, P. Pedagogia da autonomia: saberes necessários à prática educativa. São Paulo: Paz e Terra, 1996.

FREIRE, P. Pedagogia da esperança: um reencontro com a pedagogia do oprimido. Rio de Janeiro: Paz e Terra, 1997.

FREIRE, P. Pedagogia da indignação: cartas pedagógicas e outros escritos. São Paulo: Editora da UNESP, 2000.

JARA, O. H. A Educação popular latinoamericana: história e fundamentos éticos, políticos e pedagógicos. São Paulo: Ação Educativa/CEAAL/ENFOC, 2020.

MACHADO, R. C. F. Autonomia. In: STRECK, D.; REDIN, E.; ZITOSKI, J. J. (org). Dicionário Paulo Freire. Belo Horizonte: Autêntica, 2010. p. 92-93.

MINAYO, M. C. S. O desafio do conhecimento: pesquisa qualitativa em saúde. São Paulo: Editora Hucitec, 2015.

MOREIRA, C. E. Emancipação. In: STRECK, D.; REDIN, E.; ZITOSKI, J. J. (org). Dicionário Paulo Freire. Belo Horizonte: Autêntica, 2010. p. 246-247.

OSÓRIO, J. La Educacion popular latinoamericana, trayectorias debates y vigencia In: CUADRA, F.; MELO, A. A.; SANTIAGO, M. C. (org.). Intelectuales y pensamiento social y ambiental en América latina. Santiago: RIL, 2020. p. 333-348.

ROSSATO, R. Práxis. In: STRECK, D.; REDIN, E.; ZITOSKI, J. J. (org.). Dicionário Paulo Freire. Belo Horizonte: Autêntica, 2010. p. 538-540. 
A atualidade do pensamento de Paulo Freire para reinventar as práticas de formação política no âmbito...

STRECK, D. R.; REDIM E.; ZITKOSKI J. J. (org.). Dicionário Paulo Freire. Belo Horizonte: Autêntica, 2010.

VASCONCElOS, M. L. M.; BRITO, R. H. P. Conceitos de Educação em Paulo Freire. Petropólis: Editora Vozes, 2012.

ZITKOSKI, J. J. Diálogo/Dialogicidade. In: STRECK, D.; REDIN, E.; ZITOSKI, J. J. (org.). Dicionário Paulo Freire. Belo Horizonte: Autêntica, 2010a. p. 198-199.

ZITKOSKI, J. J. Pensar Certo. In: STRECK, D.; REDIN, E.; ZITOSKI, J. J. (org.). Dicionário Paulo Freire. Belo Horizonte: Autêntica, 2010b. p. 515-517.

Recebido em 10/08/2020

Versão corrigida recebida em 06/05/2021

Aceito em 11/05/2021

Publicado online em 21/05/2021 